\title{
UNDERSTANDING INSTITUTIONAL CHANGE: FAST-MOVING AND SLOW-MOVING INSTITUTIONS *
}

\author{
Gérard Roland
}

* I am grateful to Erik Berglöf, Grigore Pop-Eleches, Thad Dunning, and especially Ruth Collier for very helpful comments. I also thank seminar participants at the World Bank. 


\begin{abstract}
This article proposes a classification of institutions into "slow-moving"and "fastmoving”institutions. A prime example of a slow-moving institution is “culture,” including values, beliefs, and social norms. Fast-moving institutions do not necessarily change often but can change more quickly — sometimes nearly overnight. Political institutions can typically be viewed as fast-moving institutions. It is argued that the interaction between slow-moving and fast-moving institutions can shed light on institutional change (why it occurs, how, and when). Several implications of the analysis are drawn, and in particular the difficulty of transplanting institutions into different cultural contexts and the justification for a diversity of institutional blueprints for efficient growth and development.
\end{abstract}




\section{Introduction.}

Understanding the conditions for successful economic growth and development is becoming an increasingly central question in economics. It is the same question that Adam Smith was asking in 1776 when he founded the discipline. For many decades, the central question in economics concerned the comparison of markets and hierarchies in the allocation of resources, and was the focus of the entire general equilibrium program, but its importance in economics receded with the collapse of central planning. More recently, the very diverse performances of various developing countries and countries in the process of transition from socialism to capitalism have revived the “Adam Smith question.” For example, why has the growth performance of Russia been so dismal in its first decade of transition, whereas China has been growing at over eight percent per year throughout its two decades of transition? Why has the Argentine economy, one of the richest in the world in the early twentieth century, more or less

collapsed? Why have the "Asian tigers” experienced a successful economic takeoff, whereas the economies of most African countries have been decimated by misery, war, and disease?

The Adam Smith question is not only central in the economics of development; it is also central in economic history and transition economics. Why the early success of Britain? Why the failure of Spain to take off when Britain was industrializing? How can one explain the success of some of the latecomers to industrialization (Gerschenkron 1962) and the "modernization failures” in Egypt and large parts of the former Ottoman empire? Whereas these questions can only be answered by digging into the past, the transition experience of the nineties was both a testing ground for the traditional body of economic theory and an invaluable source of new information about conditions for successful capitalist development. It has been a humbling experience for the so-called Washington Consensus and has unveiled many weak spots in the certainties of the economics profession (see Roland 2002). It has also raised new questions and puzzles, the most important one being the Chinese "economic miracle” following a strategy quite removed from the one recommended by the Washington Consensus.

The revival of the Adam Smith question has been associated with increased support for the institutionalist school in economics (North 1990; Williamson 1975, 1985; and others). Paraphrasing Nixon, we can say "We are all institutionalists now." However, there are by now probably as many interpretations of the new institutionalist bible as there are different Protestant 
churches. What do we mean by institutions? What are the relevant institutions for successful development? Are they complements? substitutes? Is there one "first-best" set of institutions, or is the optimality of institutional systems country-specific? To what extent can "optimal institutions” be imported? How does institutional change occur? How can a country improve its institutions? All of these questions are important, and few have yet received a convincing answer.

In this paper, I try to make some progress in providing a conceptual framework that would allow us to tackle these questions. It is not my purpose to survey the literature on institutions within the field of economics, but I will discuss some of the contributions along the way. First, I discuss the approaches to institutions in the discipline of economics. Next, I propose a classification of institutions to provide a basis for understanding the interactions among institutions and institutional change. I distinguish between sets of institutions based on whether they change slowly and continuously or rapidly and irregularly. I term the former "slow-moving" and the latter "fast-moving" institutions. What is often called "culture," including values, beliefs, and social norms, can be classified as a slow-moving institution. The evolution of culture is closely related to the evolution of technology and scientific knowledge, which obviously plays an important role in understanding growth. Like culture, technology evolves slowly and continuously, although the pace may vary.

Fast-moving institutions do not necessarily change often but can change more quicklysometimes nearly overnight. Political institutions can be classified as fast-moving institutions. In this article, I take an initial look at the interaction between slow-moving and fast-moving institutions and argue that the analysis of the interaction between the two types can shed light on institutional change (why it occurs, how, and when). I suggest some preliminary hypotheses, such as the difficulty of transplanting institutions into different cultural contexts. Finally, I offer some policy implications.

\section{Posing the Institutional Question in Economics}

One of the main problems in institutional economics is that there exist myriad institutions in an economic system. Economists have taken different approaches to understanding institutions as they attempt to understand which institutions are relevant for growth and development. 


\subsection{What Do I Mean by Institutions?}

In order to identify the relevant institutions, one must first ask exactly what is meant by “institutions.” North (1990: 3) defines institutions as constraints on behavior imposed by "the rules of the game" in society: "Institutions include any form of constraint that human beings devise to shape human interaction.” This definition includes formal and informal institutions. It is a very broad definition in that it includes in particular social norms and all other constraints imposed by a society's system of beliefs and values. In that regard, from North's perspective it does not make sense to distinguish between "institutions" on the one hand and "culture" on the other as fundamentally different causal mechanisms to explain growth and development; both are institutional causes, simply different ones. North, however, explicitly excludes organizations as institutions; for example, he considers banks to be organizations, not institutions. Yet the banking system itself is shaped by the institutional system (laws and regulations related to the financial system).

Economists have modeled institutions in two alternative ways: either as exogenouslygiven constraints on behavior (following North) or as endogenously-appearing self-enforcing rules that are the equilibrium of a repeated game (Aoki 2001; Greif 1993, 1994). Institutions have no meaning if the constraints they impose are not enforced. In the exogenous models, enforcement relies (often implicitly) on the role of a third party. Such models therefore have the disadvantage of raising the questions of where these third parties derive their enforcement power and what their incentives are to enforce the rules. By contrast, Aoki’s (2001) elegant approach to institutions as endogenous, self-enforcing rules does not simply assume away the difficult question of enforcement. However, this approach is mostly tractable when one looks at relatively simple institutions like contract enforcement. In many cases, one would need to define the selfenforcing object as a large cluster of institutions. A general equilibrium approach is thus very ambitious but also quite complicated. For purposes of the (partial-equilibrium) analysis of specific institutions, it suffices to take institutions as exogenous and to understand their effects on human behavior and interaction.

To avoid adding semantic confusion, I will take as a starting point North's definition of institutions. The next (and probably more important) question is how to classify different 
institutions. Some sort of classification is important because, in order to understand an economic system, one must have a conceptual framework to understand the interactions between the various institutions at work within that system.

\subsection{Approaches to Classifying Institutions}

\subsubsection{The functional approach}

A first method of classification, often adopted by economists, is provided by a functional approach, which defines institutions by the needs of efficient contracting and investing: we need property rights to write contracts, bankruptcy laws and courts to enforce the contracts, financial market institutions to secure investment, governments to provide public goods and infrastructure, and so forth. Under the functional approach, a specific institution corresponds to each need. This is a straightforward and natural way to think about institutions.

The functional approach, however, is not without its problems. First of all, it is not straightforward to derive specific existing institutions from the needs they are called upon to fulfill. There are many different bankruptcy laws in the world. How does the functional approach account for this diversity? At best, it can provide—with some help from theory—a prescription for the optimal bankruptcy law contingent on differences in economic circumstances. For example, in an economy where agents are very risk-averse and display little taste for entrepreneurship, a bankruptcy law should not be too punitive towards failed entrepreneurs, whereas bankruptcy laws should be tougher towards debtors in an economy where agents are both very entrepreneurial and prone to cheating to make a quick buck. However, this approach does not explain adequately the choice between different institutional arrangements that fulfill the same function, or why some countries end up with inefficient institutions. A second problem is that it is difficult to say something about systems of institutions other than as an average of individual institutions satisfying particular needs. The functional approach does not tell us how institutions interact.

\subsubsection{A macrosystemic approach}

A second method for classifying institutions is provided by a macrosystemic approach. Subscribers to this approach start from a descriptive list of different institutions, going from 
general (political, legal, social) to specific categories; political institutions include, for example, regime type, electoral rule, rules affecting legislative bargaining, and the degree of federalism. This approach helps us to understand the effects of particular institutions and to perform a comparative institutional analysis, one of the main goals of the research agenda of institutional economics. Indeed, institutional description allows us to define an extensive-form game that is not arbitrarily given but that follows the description of the institution. For example, to understand the divergent effects of, presidential versus parliamentary democracies, one defines extensiveform games based on the existing constitutional features of the different political systems (e.g.,, Persson, Roland, and Tabellini 2000). Analysis of the equilibria of those games suggests which institutional details may be relevant and which may not be: the irrelevant details are the ones that, when varied or changed, do not affect the equilibrium of the game. This is a pretty foolproof method, using tools of game theory to determine which institutional details are relevant and which are not. ${ }^{1}$

Not only can the macrosystemic approach provide a natural method for understanding the effects of specific institutions, it also allows us to conceptualize and analyze systems of institutions. For example, recent research has emphasized the different sets of institutions in common law versus civil law countries (La Porta et al. 1998a, 1998b, 1999, 2000); portfolioversus bank-oriented systems of finance (e.g., Mayer 1987; Berglöf 1990); and parliamentary versus presidential systems (Persson et al. 2000); as well as in countries with different electoral rules (e.g., Lizzeri and Persico 2001; Persson and Tabellini 1999; Milesi-Ferretti et al. 2002; Persson et al. 2003), federal versus centralized government (Weingast 1995; Cai and Treisman 2001); and democracy versus dictatorship (Acemoglu and Robinson, forthcoming).

Systems of institutions are characterized by complementarities and substitutability of different institutions. This observation raises questions about the interactions among specific institutions within any institutional system. What, for example, are the interactions between antitrust institutions that foster market competition and managerial incentive structures? between incentive structures and property rights, social norms and legal arrangements, or corporate governance and labor market institutions? What is the relationship between labor-market institutions and social-insurance systems? How are economic institutions related to electoral rules and other aspects of the political system? Asking these questions about interactions between institutions seems to make the task of understanding institutions even more daunting. 
One must understand not only myriad real-world institutions but also the interactions among them. The combinations appear astronomically complex.

In practice, however, this is not the case. Kornai (1995), for example, noted a strong congruence among economic institutions for allocation of resources and forms of ownership. Institutional systems are generally not a modular construction where one module can be replaced easily by another. If this were so, "institutional shopping” would be nearly as easy as supermarket shopping. Institutions generally form a system in the sense that each institution in the system is complemented by others, achieving a certain systemic consistency. Replacing one institution by another can in some cases dangerously disrupt this systemic consistency. Piecemeal institutional change in some directions is made impossible when there are strong complementarities among institutions.

These strong institutional complementarities have figured prominently in debates about the optimal institutional reform strategy from socialism to capitalism in the former Communist countries. ${ }^{2}$ Post-socialist transition is, however, not the only example. Institutional congruence may help to explain why institutional transformation in Japan appears to be so difficult. The Japanese economy has been ailing for more than ten years, and no fundamental institutional reform has taken place. Reform-minded politicians seem to face insurmountable obstacles.

The existence of complementarities among institutions suggests that analysts should examine systems of institutions and that countries can be classified accordingly. A distinction made by Evans (1989) and picked up by Acemoglu et al. (2002) and many others (e.g., Shleifer and Vishny 1999) is that between "predatory” and “developmental” institutions. Predatory institutions allow the minority in power (usually, although not necessarily, under a dictatorship) to use its power to prey upon economic agents, thereby reducing the latter's incentive to invest and produce. Developmental institutions, by contrast, encourage development and growth by providing a "helping hand” to private agents, providing public goods like education, infrastructure, and incentives to invest. This distinction between predatory and developmental institutions is certainly the most important classification economists can think of, given the interest in the Adam Smith question.

However important this distinction, it is based on outcomes, and does not specifically identify the relevant institutions. What are the predatory institutions? What are the developmental institutions? In other words, what are the main institutional mechanisms that lead 
to stark differences in growth outcomes? Much empirical research does a poor job of dealing with these questions because the indicators used are mostly surveys among businesspeople and economic agents asking about the security of property rights. Not only are these measures subjective and imprecise, but it is difficult to tell how well they separate perceptions of bad institutions (the cause) and bad economic performance (the effect). Identifying the precise mechanisms leading to predatory and developmental institutions is important from a policy perspective. Are predatory institutions essentially the product of multiple regulations put in place by corrupt bureaucrats to extract bribes? Are they the result of an inadequate separation of power within the government and the bureaucracy? Or are they related to differences in the culture, education, and quality of bureaucrats? Clearly, different answers to these questions lead to quite different policy conclusions, reinforcing the need for a better understanding of institutional systems worldwide.

A major empirical challenge is to disentangle the relative importance of different institutions: the quality of the legal system and of law enforcement; the quality and integrity of the bureaucracy; the nature of the political regime, electoral rules, and the degree of federalism; social capital; and social norms and values. Ideally, we would be able to measure the separate effects of different institutions or the joint effect of a subset of institutions, but this task is not easy. First of all, as mentioned above, many institutions are strongly correlated. This does not pose too big a problem, however, because factor analysis allows us to deal with a large number of correlated independent variables. One can even argue that factor analysis is a good strategy for empirical research on institutions, because identification of clusters of institutional variables will be very helpful for further conceptualization of institutional systems. A bigger obstacle than correlation is the identification problem; institutions are usually not exogenous but may themselves be the product of other institutional constellations. Are legal arrangements causing social norms, or is it the other way around? Considerable craftsmanship and innovation in datasets will be required to find adequate estimation strategies to tackle those questions.

\subsection{Change and Persistence of Institutions}

\subsubsection{The functionalist pitfall}


We have seen that a functionalist approach poses important problems in the classification of institutions. Functionalism also provides the biggest pitfall in trying to understand institutional change. The functionalist view is that institutions change by necessity in response to a change in their environment that diminishes the efficiency of existing institutions; it does not explain the mechanisms by which change takes place or fails to take place. It is rather like the social scientific equivalent of the Lamarckian view that organisms evolve in order to adapt to changes in their environment (as opposed to the Darwinian view that genetic mutations are random and that, when the environment changes, the mechanism of natural selection promotes the survival of the fittest). While functionalism has been criticized at length and has been deeply discredited in the political and social sciences (e.g., Elster, 1982), it has remained quite alive in economics, where it has a long tradition from Marx to Gerschenkron. In modern economics, functionalist explanations are justified by the assumption (mostly associated with the Chicago school) that economic agents can efficiently bargain to create adequate institutions. Institutions can be seen as the result of some kind of Coasian bargain within society (see Acemoglu 2002 for a contrary view). Therefore, institutions should in general be both efficient and adapted to the existing social and economic environment.

\subsubsection{The persistence of inefficient institutions}

Decades ago, however, Olson (1972) refuted the view that institutions are the result of an efficient Coasian bargain, by emphasizing the collective action problems of large groups. The Olsonian view stands in stark contrast to the Chicago view: inefficient institutions may survive for a long time because groups with stakes in institutional change fail to get organized and solve their collective action problem. However, collective action problems are not necessarily the only reason for the persistence of inefficient institutions. Acemoglu and Robinson (2000, 2001, 2003) have emphasized the commitment problem that governments in general face, since there is usually not a third party to enforce agreements between various groups in society. Whatever group holds power will use that power in its own best interest. Thus, ruling elites who have a vested interest in maintaining their power in societies with inefficient institutions may not agree to give up that power because the winners of institutional change may not be able to commit to compensation schemes for the losers. Inefficient institutions may therefore persist because of the combined effect of social conflict and lack of commitment. For example, the Russian tsarist 
regime and the Austro-Hungarian Empire were much more resistant to change than Germany. In the former cases, aristocratic interests remained purely in land and had no commercial or industrial interests. The industrial bourgeoisie was seen as a threat to the power of the existing elite (Acemoglu and Robinson 2002). In Germany, by contrast, the Napoleonic wars had deeply shaken the powers of the landed aristocracy, and the Prussian elite experienced an interpenetration between industry and land.

So how does change come about? In the Acemoglu-Robinson models, from time to time exogenous and stochastic events give power to certain groups in society. Workers may be disorganized most of the time, but in a crisis are able to unite and have the strength to overthrow the existing regime. This model makes sense, it is important to recognize that the ability of social groups to organize depends partly on existing institutions. Dictatorships tend to systematically repress the collective action of those not in power, whereas democracy provides an institutional framework for the large majority of the poor to solve their collective action problem via political competition and elections. This is partly why universal suffrage was such a big battle at the turn of the twentieth century. For the poor, it represented an institutional change that could maintain the momentum of exceptional moments, such as general strikes, in which the collective action problem could be solved momentarily. For the rich, however, the franchise was a way to commit to redistributive transfers toward the poor while avoiding a revolution (Acemoglu and Robinson 2000).

A key insight from this discussion is that institutions impact the ability of different groups in society to solve their collective action problems. Therefore, institutional change is itself the object of political and social conflicts.

\section{A Framework for Understanding Institutional change}

In order to have a meaningful understanding of institutions as systems, we need to understand interactions between different institutions. We must also have a way to understand institutional change. To make some progress along these lines, I propose a classification that is based on the capacity of institutions to change rapidly or slowly, and whether or not that change is continuous. 


\subsection{Fast-moving and Slow-moving Institutions}

I start with a fundamental distinction between slow-moving and fast-moving institutions. The former generally change slowly, incrementally and continuously, whereas the latter are more given to rapid, discontinuous change in large steps. Political institutions, for example, have the potential for centralized decisional changes in large steps. In this sense, they can be fast-moving institutions, which change nearly overnight when there are revolutionary moments. In contrast, social norms are more often an example of slow-moving institutions. While some social norms and values can change very rapidly in historical terms (e.g., a society’s tolerance for cigarettes), in general, social norms and values change slowly. Even individual social norms, such as attitudes towards the death penalty or acceptance of corruption, tend to change rather slowly, possibly because many norms are rooted in religions whose basic precepts have changed remarkably little for centuries and even millennia; the major world religions have shaped and still shape the basic values and preferences of individuals, what they consider important in life, and how they expect other people to behave toward them. One can always find examples to the contrary, but values and social norms, seen as a whole, tend to change slowly.

It is not my purpose here to analyze why social norms or values change slowly, but simply to state the fact. An important element, however, is whether or not institutions can change by authoritative decision. Legal systems tend to be faster-moving institutions than social norms but slower-moving than political institutions. A given law can be changed overnight, but legal systems are rarely changed as rapidly as political institutions, such as electoral rules. On the other hand, the effectiveness of the legal system and the enforcement of laws depend on their acceptance and legitimacy in society and on the expectations of many actors. Thus the legal system is very similar to social norms, except that the system of rewards and punishments is legally codified and can be changed more rapidly than social norms, which can never change by fiat.

I also wish to add a word about which institutions tend to change continuously and which discontinuously. Compared to social norms, political institutions may change more discontinuously; they may change little for prolonged periods of time, then change very abruptly. Social norms, on the other hand, tend to change continuously, albeit slowly. ${ }^{3}$ Legal arrangements are again somewhat in between. While the size of the increments of change and the extent to 
which change unfolds continuously or discontinuously are not identical concepts, there is an obvious, close relationship between these two aspects of slow- and fast-moving institutions; if steps of change are large but are taken rarely, for example, change occurs discontinuously.

What is the relationship between fast- and slow-moving institutions? Slow-moving institutions are by definition good candidates to influence fast-moving institutions, since the former may change little at a time when the latter is changing dramatically. On the other hand, for this perspective to make any sense, slow-moving institutions must also change continuously, so as to produce inconsistencies with fast-moving institutions and thereby create pressures for change. An appropriate analogy is an earthquake: pressures along fault lines build up continuously but slowly, then suddenly provoke an earthquake that abruptly changes the topography of a given area. Slow-moving institutions are the equivalent of these tectonic pressures; fast-moving institutions are the equivalent of the topography.

Marx's theory of institutional change has some parallels to the one posed here. What he called "productive forces" are analogous to slow-moving institutions, in that they change slowly and continuously yet create pressures for change in what Marx termed the "superstructure" (what I term “fast-moving institutions”). However, technology was the main component of Marx's productive forces, and technology is not an institution. Thus, the Marxian scheme classified all institutions as part of the superstructure, including (following the philosopher Ludwig Feuerbach) ideas and culture. However, seen as the broader set of both social norms and values, culture is typically a slow-moving institution, one that influences fast-moving institutions. The present model thus differs from that of Marx, and is, in a sense, closer to Max Weber's emphasis on the importance of culture in explaining institutional and economic change. The approach described in this article is, in that sense, neo-Weberian.

\subsection{Technology, Culture, and Growth}

Technology is a fundamental explanatory factor for economists seeking to understand growth. Technology is the accumulated stock of knowledge embodied in human society. Where does technology stand in our analytical scheme? Technology relates to a broader set of beliefs about the operation of the physical world and about the nature of interactions between humans 
and their physical environment. Culture, by contrast, comprises social norms, which refer to ideas about interactions among human beings, and the broader set of underlying values.

However, culture and technology have many things in common. Both tend to evolve continuously and slowly, although technology may be more prone to irregular bursts of change clustered around particular moments in time. Both involve research and experimentation, trial and error, and learning. Education is the acquisition of both technology and culture. Moreover, the evolution of technology and culture are difficult to predict because they obey the laws of the evolution of knowledge: both are subject to unpredicted innovations that emerge in association with random, mutation-like recombinations of subsets of the existing stock of knowledge. These commonalities between culture and technology also mean that they evolve in parallel. Sets of beliefs related to technology influence sets of beliefs related to interactions among humans.

Culture, understood in terms of social norms and underlying values, must therefore be analyzed in conjunction with technology and with the growth of knowledge. Just as we are familiar with analyzing technological innovation and its role in economic growth, we should also look at cultural innovations and analyze their broad social and economic effects. Examples in history abound. Different societies have throughout history exhibited different attitudes toward manual labor and work in general, toward thrift and usury (and even toward the use of interest rates), toward respect of private property and of creativity, and towards the participation of women in different economic activities. Obviously, these cultural differences have had a profound impact on economic development and growth.

It is in a way strange that most economists have shied away from incorporating cultural differences and cultural innovations in economic analysis. ${ }^{4}$ The process of economic growth tends currently to be seen by economists as a combination of technology and institutions. I propose to view institutional change as the interaction between slow-moving institutions, culture in particular, and fast-moving institutions such as political and legal institutions. It is this interaction that drives institutional change, and it is the interaction between institutional change and technology that drives economic growth.

\subsection{Interests and Institutional Change}


An important question arises: If Olsonian interests play an important role in processes of institutional change, how should we understand the causal role of slow-moving institutions? Are they redundant as an explanatory factor? Change is driven by social forces that favor it and opposed by social forces that would lose from it. The balance of power between those two groups determines the dynamics of change. Yet, how the relative strengths of forces of change and of conservatism map onto conflict and change also depends on the existing institutions, on how they help or hinder groups in solving their collective action problem, and on how representative and participatory the political institutions are.

While it would, therefore, be wrong to exclude the role of interests from discussions of institutional change, interests are not sufficient either to explain why institutional change takes place or to elucidate the direction of change. The institutional changes that took in Western Europe in the eighteenth and nineteenth centuries would be difficult to imagine without the intellectual turmoil created by the Renaissance and the ideas of the Enlightenment, which were spread by communication technology such as the printing press. Ideas of equality and human rights led to enormous changes in forms of government, and to the long transition from absolutism to democracy. This contrasts sharply with China, where Confucianism and related ideas were miles away from the Renaissance and Enlightenment ideas. China has experienced time and again large rebellions of peasants (larger than in ancient Rome or feudal Europe), some of which even managed to overthrow the empire. However, given the ideological background of these revolts, most only led to a change of emperor or of dynasty, because the purpose of the rebellion was to replace the emperor with a "more just" one.

The interests of oppressed groups always play an important role in institutional change. However, the ability of oppressed groups to organize often relies on commitment to particular world-views. On the one hand, oppressed groups are often mobilized by elites who are driven by certain ideologies or world-views. The October Revolution in Russian is probably a good example: organized elites with a certain world-view managed to seize power in a situation of semi-anarchy after a military defeat. On the other hand, solving collective action problems of oppressed groups also depends on rank-and-file militants who care so much about the ideas they fight for that they are ready to pay enormous costs (often, their lives). To these people, the freeriding incentive that may normally bedevil collective action does not apply. Thus there is an important role for culture, worldviews, and ideological commitment in explaining institutional 
change. Thinking that only interests drive institutional change implies the dangerous assumption that economic prosperity will make Islamic fundamentalism quietly disappear.

\section{Some Hypotheses using this Framework}

To shed light on the Adam Smith question with which I began, it is necessary to understand how the interaction of slow- and fast-moving institutions creates pressures for institutional configurations that may be growth-enhancing or growth-inhibiting. This interaction is not onesided: slow-moving institutions exercise causal pressures on fast-moving institutions, and, by the same token, the latter have a life their own and can influence the path of slow-moving institutions. Moreover, different slow- and fast-moving institutions may have different effects on economic growth in their own right, while the form of existing fast-moving institutions may promote or, alternatively, may inhibit further institutional change, with positive or negative implications for economic growth.

These issues are quite complicated and demand a major research effort in many directions. Nonetheless, in this section, I use the framework developed above to suggest some working hypotheses about the institutional conditions for successful economic growth and development.

\subsection{The Failure of Institutional Transplantation}

A first hypothesis is that transplanting institutions is likely to be unsuccessful. Support for this hypothesis is provided by the fact that transplantation of European institutions did not work well outside the settler colonies. Colonial settlers transplanted European institutions, fast-moving by definition, into a setting to which they brought their stock of knowledge, their technology, and their culture. The countries that grew from these settler colonies are now counted among the rich, advanced economies of the world. Contrast this economic outcome with post-colonial India, where British institutions were transplanted into a different cultural context, including a deeply rooted caste system. An even stronger contrast is Africa, where conscious attempts to introduce the Western-style institutions of the democratic, modern European nation-states pathetically failed to produce economic growth. Transplantation often does not work well precisely because 
institutions are characterized by the complex interaction between slow-moving and fast-moving institutions, and the former change slowly and are largely autonomous. Trying to impose Western fast-moving institutions adequate to the West's own slow-moving institutions in countries with a very different history and culture is not likely to meet the same economic success.

The interaction between slow-moving and fast-moving institutions thus provides an explanation for why the transplantation of "best-practice" institutions (or "institutional monocropping” ${ }^{5}$ ) does not work. It provides content to the idea that different countries have different "local conditions," which arise from each country's slow-moving institutions. It also provides a rationale for why reforms in a given country must build on these local conditions. In other words, countries with different cultural and historical paths must find within their existing slow-moving institutions the roots for changes in their fast-moving institutions.

\subsection{The Advantage of Accumulated Knowledge}

Another hypothesis stems from a "Jared Diamond" (1998) vision of the world, which proposes to explain the unequal development of civilization by the differences in the initial conditions facing early humans. Focusing on domesticable plants and animals and the (latitudinal or longitudinal) shapes of the continents, Diamond argues that the best conditions for developing civilizations were met in Eurasia, and within Eurasia, mostly in the Middle East and the Mediterranean. Favorable initial conditions led to population growth, which led in turn to higher production of surplus via division of labor. The latter led in turn to a higher production of knowledge, both scientific and cultural.

Let us take as a starting point this stock of knowledge dating to antiquity in the Mediterranean. This higher stock of knowledge does not refer only to scientific knowledge; the study of mathematics in Ancient Greece was more developed than anywhere else in the world, but the region's cultural diversity was also quite impressive, as evidenced by the number of competing religions in the Mediterranean at that time. Institutional innovation was also thriving: the variety of political systems in the region was much greater than elsewhere. Most of the forms of government known throughout history were invented in the Mediterranean and in the Old 
World (Finer, 2001); even today, “old Europe” is experimenting with supranational forms of democracy at the level of the European Union.

The evolution of knowledge and culture may be linked to political institutions; the vigorous development of technologies suggests the parallel development of ideas concerning political innovations. Indeed, it is reasonable to think that innovation should apply not only to technology but also to the political and social spheres (although, since social and political innovations are much more costly to experiment with than are technological innovations, they may occur less frequently). Since knowledge and culture accumulate slowly, geographic areas with environmental conditions that promoted the interaction of diverse cultures, and hence, large stocks of accumulated knowledge, may have had greater potential for fast-moving institutional change. It may, therefore, be no coincidence that Europe, historically diverse and geographically favorable to interaction between cultures, was the location of most of the political innovations throughout history. How can we explain Western Europe's economic dominance over much of the rest of the world in the last several centuries? One hypothesis is that the initial conditions proposed by Diamond favored a cross-cultural exchange of ideas, and that this exchange permitted an accumulation of knowledge that gave Europe an institutional "head start”. ${ }^{6}$

\subsection{Accumulated Stocks of Knowledge}

Europe, of course, did not experience an uninterrupted accumulation of knowledge, a fact which suggests that countries with accumulated knowledge may witness historical setbacks for prolonged periods due to war or internal institutional failures. However, to the extent that stocks of knowledge and cultural capital remain preserved, these countries may be positioned for a more solid growth path once they are on a favorable track as far as their fast-moving institutions are concerned. Flanders, for example, experienced a cultural flowering during the Middle Ages and early Renaissance, when it was one of the richest areas in the world, and even recovered (albeit centuries later) from the massive losses inflicted by the Spanish Inquisition.

Consider also the case of China: the twentieth century was certainly one of the worst in all of Chinese history, but until the seventeenth or eighteenth century, China had the most advanced economy in the world. While Europe, despite its earlier superiority in terms of the development of knowledge, _was mired for centuries in bloody wars, China developed its economy through 
centuries of relative peace and remarkable institutional stability equaled only by ancient Egypt. Since then, China has undergone more than two centuries of relative decline. However, considering the success of Chinese transition, with an average growth rate of over $8 \%$ per year, it is difficult not to think that there is not some kind of "reversion to the mean" and that the accumulated knowledge and culture from the country’s past have helped in this process. Sachs and Woo (1992) present almost the opposite perspective, attributing China's recent high growth rates to the country's "backwardness” in the immediately preceding period. Seen in a long-run historical perspective, however, China has been anything but backward. For example, Chinese agriculture, which was the initial engine of growth early in the transition, has always been among the most productive in the world. I therefore suggest that one of the clues to the success of China's transition is not its "backwardness" at the onset of the transition but the inherited high level of knowledge and culture relative to its economic performance.

Based on its existing stock of cultural knowledge (which differs strongly from that in the West), China, like other Asian countries, has developed unique fast-moving institutions in achieving its recent growth trajectory. Thus, China is experimenting with its own institutions for the market economy instead of importing Western institutions. Whether Asian capitalist institutions are more efficient is not the right question to ask here. A more appropriate question relates to the one posed earlier about institutional transplantation: what would have happened if Western-style institutions had been directly imported into a cultural context that exhibits deep differences from those of the West?

\subsection{Dictatorship and Growth}

Whereas we have seen above that the transplantation and development of fast-moving institutions is affected in important ways by slow-moving institutions, one-way causality is not necessarily implied. Fast-moving institutions may impede the development or deployment of stocks of knowledge. In the context of the modern "knowledge economy," the most important impediment to growth for countries beyond a certain level of economic development may be repressed circulation of ideas. Countries governed by totalitarian dictatorships may fall behind in economic development. 
This hypothesis is compatible with Przeworski et al.'s (2000) finding that dictatorship may be at odds with modern economic development. It may also help to explain the economic trajectory of the Soviet Union, in which, after several decades of successful industrialization under a repressive centralized regime, economic growth slowed significantly during the 1970s and 1980s; the new "computer age" was incompatible with the Communist regime's attempts to control the use of typewriters, photocopiers, and other tools for widespread communication. Similarly, if the Chinese Communist regime continues to limit access to the Internet, this will undoubtedly have negative economic consequences. Of course, not all dictatorships repress the exchange of knowledge. For example, pro-business dictatorships do not generally attempt to exercise totalitarian control over the circulation of ideas. Nevertheless, it is still clear that dictators try to prevent the free circulation of any ideas that may hurt them politically. Since intellectual freedom is a precondition for innovation and technological and cultural creativity, institutions that encourage the circulation of ideas may be increasingly necessary for growth in a global, information-based economy.

\subsection{Concentration of Power Affects Institutional Change}

The form of fast-moving political institutions may greatly affect the manner in which institutional change occurs, with important consequences for economic development and growth. In particular, this subsection focuses on the implications of the relative (de)centralization of political power for the dynamics of institutional change.

Although much work remains to be done, recent research suggests that decentralization through federalist democracies encourages experimentation. American federalism is often considered a "laboratory of the states," where some states initiate and experiment with innovative institutions. Other states may imitate the successful results (see the framework of Qian, Roland, and Xu 1999 on flexibility and organizational forms). At the other extreme, as discussed above, totalitarian regimes are likely to prevent not only technological and cultural but also political innovations, resulting in pronounced institutional uniformity and rigidity. Even in centralized democratic states, such as France and Japan, major changes in government programs, such as education and banking reforms, require initiation by the responsible ministries and coordination by the central government. 
The degree of centralization and power concentration has important implications not only for institutional experimentation but also for the nature and speed of political change. Political institutions that concentrate power in the hands of a few tend toward patterns of infrequent and abrupt change because, relative to institutions in which power is more dispersed, institutions with concentrated power leave more room for discretionary behavior and abuse of power by those holding office. As a corollary, the high economic stakes of political power in centralized regimes tend to translate into a more pronounced temptation to resort to coercive methods to retain power.

Many historical examples illustrate this phenomenon. One is the well-known comparison between the evolution of the British Crown and that of absolute monarchy in France. The English monarchy was historically relatively weak, and in consequence the king had to share powers with feudal lords. Frequent attempts to strengthen the power of the king were mostly defeated. Although the episode of the Glorious Revolution of 1688 and the subsequent separation of powers between the monarch and the House of Lords - one of history's most important political innovations — has been documented at length (e.g., North and Weingast 1989), previous episodes, such as the drafting of the Magna Carta in 1215, reveal a constant check on the king by the feudal lords in medieval England. Importantly, the English political system is also probably the prime example of an evolutionary political system that has adjusted in a flexible way throughout the last centuries.

Consider, by contrast, the consequences of centralized power in France: ironically, the French king began much weaker relative to noble lords than the English monarch, and remained so for centuries. It was only much later, in a Europe divided by religious wars, that the power of the French monarchy began to strengthen, until it achieved its absolutist status under Louis XIV. It took the French Revolution, centuries later, to trigger abrupt political change. Unlike the flexible and evolutionary political system that arose due to the separation of powers in medieval England, then, the centralization of power in France under an absolutist monarch made political change particularly discontinuous.

Another example comes from the comparison of the Ottoman Empire and feudal Europe. Machiavelli noted in The Prince that it was much easier to conquer feudal France than the Ottoman Empire, but it was much more difficult to occupy the former than the latter. In France, prior to the concentration of power by an absolutist monarch, feudal lords were relatively 
independent and did not rely much on the king. Therefore, they were not very loyal to the latter and would change allegiance whenever it best suited their interests. They could therefore be easily bribed by a would-be conqueror into betraying the French king. By the same token, however, feudal lords could also betray any occupying power. By contrast, the governors of the Ottoman empire had no property of their own and depended for their resources on the emperor, who threatened to have them executed if they lost territory to an enemy. Therefore, they would fight to the death against any occupant. On the other hand, once successfully invaded, Ottoman territory was easily occupied because the Ottoman institutions collapsed like a house of cards. More centralization in the Ottoman Empire therefore meant that change through successful invasions was less frequent and more abrupt when it came, whereas greater dispersion of power in pre-absolutist France allowed for more frequent foreign influence and institutional change.

However, pre-existing institutional patterns (such as centralized systems of governance) do not automatically translate into preordained trajectories of institutional change. The comparison between the transitions in China and the Soviet Union is instructive in this regard. In the former, a commitment to safeguarding some of the crucial political and economic interests of potential losers, the Communist Party old guard, allowed reformers to maintain the support of conservatives and brought with it an incremental process of change. In the latter, by contrast, the lack of such a commitment provoked a backlash by potential losers and, with it, discontinuous change.

Let us consider this comparison between China and the Soviet Union in more detail. In principle, one would think that institutional change in the transition from socialism must proceed in one leap, because power was concentrated in the hands of a relatively small group, the “nomenklatura.” However, it is wrong to claim that the nomenklatura was consistently against transition to the market economy. Indeed, many members of the nomenklatura were among the first to become successful entrepreneurs and directors of privatized enterprises. Socialist economies were distinct in the sense that few identifiable social groups could be directly labeled ex-post as "losers" or "winners" from transition; instead, the constellation of winners and losers crossed all levels of society (Roland, 1989). Thus, even though power was concentrated in the hands of the nomenklatura, reform packages could potentially be designed that lowered the stakes and facilitated a more continuous kind of political change. 
In China, although the old guard within the Communist Party had much to lose from institutional change, Deng Xiaoping, the father of Chinese economic reforms, proceeded in two ways $^{7}$. First, he launched a gradualist strategy, hoping that the first economic reforms would be successful. He thus started out with the reforms that would have the highest likelihood of being popular (see Roland 2000 for analysis). In fact, decollectivization turned out to be a huge success, which strongly reinforced the position of Deng within the Communist Party. However, despite the success of the changes, the Party's old guard became increasingly nervous because they were afraid that this process of institutional change would eventually lead to their demise. Deng therefore constantly tried to show that he was committed to not excluding them from power. For example, at times of protest such as the Wall of Democracy in 1980 or the Tiananmen Square events, Deng never hesitated to purge reformist Party leaders who were in favor of greater dialogue with student protestors. In this way, he managed to show his commitment to not purging the old guard. Later on, this commitment was institutionalized by introducing an age limit for party cadres and introducing a favorable retirement package for the older conservative communist leaders, which now works to ensure a smooth rotation of the leadership and creates an element of stability.

It is interesting to contrast this pattern of reform with the experience of the Soviet Union. When Gorbachev came to power, the Central Committee of the Soviet communist party was entirely composed of Brezhnevites, partisans of stagnation (Brezhnev's period was called zastoinyi period or "stagnation period”). Gorbachev nevertheless managed to maneuver very adeptly within the first two years he was in power to replace the Central Committee and introduce like-minded politicians who wanted change - that is, those elements of the nomenklatura who were interested in reforms (see Roland, 1991; Hough, 1988). His glasnost and perestroika programs were challenged not only by conservatives but also by Yeltsin, who favored more radical reforms that were totally unacceptable to the conservative wing of the Communist party. Unlike Deng in China, Gorbachev was not willing to repress radical reformers in order to show his commitment to the old guard. Furthermore, unlike Deng, Gorbachev had not been able to strengthen his position sufficiently with successful economic reforms, The most positive thing he did on the economic front was to introduce cooperatives, the early form of small private enterprise, but their effect was relatively meager. On the negative side of the ledger, Gorbachev also made economic mistakes such as granting more autonomy to enterprises, 
which had an inflationary effect that, given the absence of free prices, only led to increased shortages.

Thus, whereas Deng had been able to lower the stakes of holding on to power and commit not to purge hard-line elements, thereby pacifying elements of the old guard, Gorbachev soon turned conservative elements against him. His unwillingness to repress reformers was felt quickly in the satellite states, which seized the opportunity to overthrow their own Communist regimes in 1989. For example, Gorbachev intervened personally during the East German events to prevent Honecker and the hard-line communists from firing on demonstrators in Leipzig. When the Soviet republics began preparing to break away, and especially when East Germany joined Germany and NATO, conservatives saw things getting out of control. They thus staged the coup that ousted Gorbachev, led to a complete implosion of the communist regime, and ultimately propelled Yeltsin to power. Thus, in neither the Chinese nor the Soviet cases did the pre-transition concentration of power in the hands of the nomenklatura inevitably lead to abrupt, discontinuous institutional change. Instead, the particular strategies chosen by reformist leaders such as Deng and Gorbachev influenced the extent to which power seemed "indivisible" to hardline elements. Further research should trace the conditions under which the implications of concentrated power for the discontinuity of change may be mitigated, as in the Chinese case, and thus lead to gradualist trajectories of reform

\section{Some Policy Implications}

The interaction between slow-moving and fast-moving institutions implies that different cultural paths (slow-moving institutions) may affect the appropriate choices of fast-moving institutions. Given our limited knowledge of these interactions, caution is required. Yesterday's conventional wisdom has often been overturned. Sixty years ago, most intellectuals were convinced that central planning was more efficient than markets. Hardly anybody believes that today. Similarly, only ten years ago, Asian economies were praised for the marvelous effect of Confucian values (family, hard work, and savings). Yet, when the Asian economies were hit by the 1997 crisis, "crony capitalism" became the only term used to name those economies. This discussion carries a number of possible policy implications. 


\subsection{The Dangers of Transplanting "Best-Practice” Institutions}

First, one should take a skeptical attitude towards transplantation of institutions, because the different dynamics of slow-moving institutions may make some fast-moving institutions inadequate in some countries. The above framework provides a rationale for such skepticism. The appropriate question for analysts of development may not be what constitutes a globally optimal set of institutions, but rather whether fast-moving institutions are appropriate to the slow-moving institutions with which they interact. Thus reforms of fast-moving institutions in a given country must in part build on existing slow-moving institutions that have arisen in countries with different cultural and historical pasts. Ignoring these pasts in designing institutional reforms is likely a recipe for failure. The interaction of slow- and fast-moving institutions therefore provides an important cautionary to any development specialist seeking to export "best-practice" institutions.

\subsection{The Importance of Gradualism and Experimentation}

Second, our current relative ignorance about the interaction between fast-moving institutions and the slow-moving institutions of different countries provides a strong rationale for certain kinds of experimentation and gradualism and, conversely, a strong reason for opposing the imposition of irreversible institutional change in a given country. Dewatripont and Roland (1995) and Roland (2000) have shown that in the presence of aggregate uncertainty about largescale institutional change, as well as high costs of institutional reversal, the optimal approach to institutional reform is gradualism. Indeed, gradualism provides an option of early reversal if the prospects look bad after the introduction of the first reforms, an option that actually makes it easier to gain political support and build constituencies for institutional change.

As I stressed above, this gradualist approach has been followed in the Chinese success story of transition from socialism to capitalism. The transition process started with decollectivization in agriculture, which itself was preceded by experiments of decollectivization in different provinces. The experimental approach was later used again and again, whether with the special economic zones or with privatization (see Naughton 1995; Qian 2002). The territorial organization of the Chinese government, following the pattern of the M-form organization 
(Chandler 1962; Williamson 1975), in contrast to the functional organization of the Soviet government, following more the U-form organization, has provided a more flexible framework for setting up reform experiments (see Qian and Xu 1993; Qian, Roland, and Xu 2000). The dual-track approach to reform has also provided a smart way to reform gradually while respecting the complementarity of reforms. Thus with dual-track price liberalization, the planned production obligations and planned delivery rights of enterprises under the plan were frozen at a preexisting level, and enterprises had continuing obligations and rights under the plan track. On the other hand, enterprises were given freedom to set prices, contract, and retain profits from transactions on the new market track. The dual-track system therefore allowed for the introduction of liberalization across all markets — which avoids the distortions that arise from liberalization only in some markets-while avoiding the disruption of output collapse by maintaining a frozen plan track (Roland and Verdier 2000). Moreover, price liberalization at the margin has the same efficiency properties as full liberalization (Lau et al. 1997) and the dualtrack has the attractive property of being Pareto-improving - that is, hurting no-one while improving the welfare of others (Lau et al. 2000). Notice also that the dual-track approach reduces reversal costs, which makes adopting it even more attractive.

Rodrik (1999) documents the positive experience of reform in Mauritius in the light of a dual-track strategy. Mauritius established an export processing zone operating under complete free-trade and free-market principles in 1970, while keeping the domestic sector highly protected until the 1980s. Moreover, the country kept the two sectors as segmented as possible to prevent negative spillovers (of wages, in particular) from the export processing zone to the domestic sector. The development of the former had a positive impact on the domestic economy that could pave the way for later liberalization. Interestingly, this was done in a very participatory political context where most interests of the population had to be involved in the decision-making process in a way similar to those mentioned by Evans (this volume) when discussing the effect of participatory institutions ${ }^{8}$.

\subsection{The Importance of Policy Dialogue}

A third implication of this discussion is, therefore, that policy dialogue may be needed more than trying to impose “one-size-fits-all” solutions for different countries. Policy dialogue has 
been viewed with suspicion in the past, on the grounds that a doctor does not dialogue with his patient about making a health diagnosis. This suspicion was based on the doubly erroneous view that technocrats in international financial institutions possess superior knowledge about economic development and that local elites either have mostly "wrong” views about solutions for their countries or lack the incentives to do something about it. As the preceding discussion has suggested, however, while slow-moving institutions may hamper the proper functioning of implanted fast-moving institutions, local knowledge about a country’s slow-moving institutions is not part of the problem but part of the solution. Therefore, only dialogue can help formulate adequate development policies. This does not mean that there are no local elites with vested interests in maintaining inefficient institutions. Yet those are not the local elites with which a fruitful dialogue can be established; rather, one should enter into a dialogue with elites who have an interest in development. Such elites are not necessarily represented in governments but are very active in civil society. Policy dialogue therefore entails not just a dialogue with governments but also with different components of civil society at large.

A few further comments are in order before closing. First, one hypothesis outlined above concerned the importance of the separation of powers in promoting experimentation (federalism) as well as in engendering continuous, flexible institutional evolution. A caveat is important here: although different forms of separation of powers diffuse the powers of government, there is a danger that this may go too far. Involvement of many different groups in decision-making may lead to an excess number of veto players, which may be stifling and prevent institutional innovation (Olson 1982). In such cases, the danger of anarchy looms. Government resources can come to be treated as a common pool into which different groups can dip their hands. The common-pool problem is a feature of many modern democracies and tends to lead to budgetary disasters, Argentina being a particularly salient example. There is thus a fine line between healthy separation of powers within governments and forms of anarchy within governments (see Persson, Roland, and Tabellini 1997 on the difference between separation of powers and the common pool problem). This shows the necessity of comparative political analysis to achieve a better understanding of how the different democratic systems function.

Second, anarchy is the big challenge at a global level today. Globalization of markets has created the need for provision of international public goods (e.g., environmental preservation, peace, disease prevention, free movement of goods and services, global financial stability). 
However, we lack adequate institutions at the world level to tackle these problems. Here, we are still closer to anarchy and generalized free-riding than to a democratic international order. These issues have become increasingly acute in the last few years. Nonetheless, constituencies may be forming to demand such an institutional change, as globalization of the economy, of science and knowledge, and of cultural interactions leads to increased demands for such changes.

\section{Conclusion}

Let us return to the bigger questions, and in particular to the Adam Smith question. Why did England industrialize more quickly than continental Europe? Why has development failure in the last few decades been so massive in so many areas of the world, with the exception of Asia? Why is China so successful in its transition? Explaining these phenomena via differences in institutions across countries begs the question of how the different institutions have evolved in different countries, which depends to a certain extent on how preexisting institutions have empowered different groups in society so that they could solve their collective action problem. This in turn begs the question of how these preexisting institutions came about. It seems that the reasoning must stop either at specific exogenous events at some points in history or that we must go down the entire path of human history. This is not quite infinite regression, but in history, one cannot go further than that.

But even if we look to history to explain institutions, how can we be sure that the subsequent chain of events obeys a predictable pattern? Are some institutional changes or their absence necessarily the consequence of preexisting institutions, or is there an infinity of possibilities, in which case it would be futile to try to establish strong causal links? How can one distinguish between predictable patterns of institutional change and purely random historical events?

These are obviously hard questions. Above, I have proposed a framework for thinking about institutional change. In order to have a meaningful understanding of institutions as systems, we need to understand interactions between different institutions. The proposed classification of institutions is intended as a step in understanding institutional change. These suggestions are still very tentative. Much empirical work is needed to better understand the interactions between different institutions. We also need better to ground empirically our knowledge of the determinants of institutional change. This will require a major effort not only for those who study 
development and transition but perhaps most of all for economic historians, because history provides a very rich ground for studying institutional change.

Nonetheless, the framework I have outlined above may be one helpful way to start thinking about institutional change. Economists have been reluctant to discuss the relationship of social norms and cultural values to economic growth. Instead, recent cutting-edge work in economics has proposed economic growth as a product of the combination of ideas and institutions. Yet ideas are closely related to culture, understood both as values (world-view) and as social norms. And as I have suggested in this paper, institutions may themselves be viewed as the interaction of fast-moving (political) and slow-moving (cultural) institutions. In order better to understand the determinants of economic growth, then, economists should seek a better understanding of the role of values and norms in shaping both ideas and institutions. 


\section{REFERENCES}

Acemoglu, D. (2002) "Why Not A Political Coase Theorem? Social Conflict, Commitment and Politics”, mimeo MIT.

Acemoglu, Johnson and Robinson (2001) “Colonial Origins of Comparative Development: An Empirical Investigation”, American Economic Review, 91, pp 1369-1401

Acemoglu, D. and J. Robinson (2000) "Why Did the West Extend the Franchise? Democracy, Inequality, and Growth in Historical Perspective”,

Quarterly Journal of Economics, 115, 1167-1199.

Acemoglu, D. and Robinson (2001) “A Theory of Political Transitions “,American Economic Review 91, pp. 938-963.

Acemoglu, D. and J. Robinson (2002) “Economic Backwardness in Political Perspective” mimeo.

Acemoglu, D. and J. Robinson (2003) Political Origins of Democracy and Dictatorship, Book manuscript.

Aoki, M. (2001) Toward a Comparative Institutional Analysis, MIT Press, Cambridge Mas.

Baron, D. (1998) “Comparative dynamics of parliamentary government", American Political Science Review 92 : 593-610.

Berglöf, E., 1990, "Capital Structure as a Mechanism of Control: A Comparison of Financial Systems", in Masahiko Aoki, Bo Gustavsson, and Oliver Williamson, (eds.), The Firm as a Nexus of Treaties, European Sage.

Cai, H. and D. Treisman, "State Corroding Federalism: Interjurisdictional Competition and the Weakening of Central Authority," mimeo UCLA.

Che, J. and Y. Qian (1998)"Insecure Property Rights and Government Ownership of Firms" . Quarterly Journal of Economics, 113(2), pp. 467-496.

Dewatripont, M. and G. Roland. (1995) “The Design of Reform Packages under Uncertainty.” American Economic Review 85: 1207-23.

Diamond, J, ( 1998) Guns, Germs and Steel, Norton Publishing Press, New York.

Diermeier, D., H. Eraslan and Merlo (2003) "A structural model of government formation," Econometrica forthcoming. 
Djankov, S. E. Glaeser, R. La Porta, and F. Lopez-de-Silanes and A. Shleifer (2003) “The New Comparative Economics" forthcoming, Journal of Comparative Economics.

Elster, J. (1982) "Marxism, Functionalism and Game Theory: The Case for Methodological Individualism." Theory and Society,11(4):453-482.

Evans, P. (1989) "Predatory, Developmental and Other Apparatuses: A Comparative Political Economy Perspective on the Third World State," Sociological Forum. 4(4):561-587.

Evans, P. (this volume) “Beyond "Institutional Monocropping”: Institutions, Capabilities and Deliberative Development”.

Finer, S.E. (2001) A History of Government from the Earliest Times , Oxford University Press, Oxford.

Gerschenkron, A, (1962) Economic Backwardness in Historical Perspective, F.a> Praeger New York, 1962.

Greif, A. (1993) “Contract Enforceability and Economic Institutions in Early Trade: The Maghribi Traders’Coalition”, American Economic Review , 83 (3): 525-48.

Greif, A. (1994) “Cultural Beliefs and the Organization of Society: A Historical and Theoretical Reflection on Collectivist and Individualist Societies” Journal of Political Economy102 (5): $912-$ 50.

Haggard, S. (this volume) “Institutions and Growth in East Asia”.

Hough, J. (1988) Opening up the Soviet Economy Brookings Institution.

Kornai, J. (1995) Highways and Byways, MIT Press, Cambridge Mass.

Kornai, J. (1980) Economics of Shortage. Amsterdam: North-Holland.

La Porta, R, F. Lopez-de-Silanes, A. Shleifer, and R. Vishny. 1998a. “Law and Finance.” Journal of Political Economy 106: 1113-55.

—. 1998b. "Legal Determinants of External Finance.” Journal of Finance 52: 1131-50.

—. 1999. “Corporate Ownership around the World.” Journal of Finance 54: 471-517.

—. 2000. “Agency Problems and Dividend Policies around the World.” Journal of Finance, 55: 1-33.

Lizzeri, A. and N. Persico, (2001) “The Provision of Public Goods under Alternative Electoral Incentives” American Economic Review , 91(1): 225-45.

Mayer, C. (1987) “Financial Systems and Corporate Investment”, Oxford Review of Economic Policy, 
Milesi-Ferretti, G-MA. R. Perotti and Ma. Rostagno (2002). "Electoral Systems and the Composition of Public Spending" Quarterly Journal of Economics.

Naughton, B. (1995) Growing Out of the Plan. Cambridge University Press, Cambridge.

North , D. (1990) Institutions, Institutional Change and Economic Performance, Cambridge University Press, Cambridge.

North, D. and B. Weingast (1989), "Constitutions and Commitment : Evolutions of Institutions Governing Public Choice", Journal of Economic History, vol. 49, pp. 803-832.

Olson, M. (1971) The Logic of Collective Action: Public Goods and the Theory of Groups. Cambridge, Mass.: Harvard University Press.

Olson, M. (1982) The Rise and Decline of Nations, Yale University Press.

Persson, T. and G. Tabellini (1999) "The size and scope of government: Comparative politics with rational politicians", Marshall Lecture, European Economic Review, : 699-736.

Persson, T. Roland, and G. Tabellini,G. (1997). "Separation of Powers and Political Accountability", Quarterly Journal of Economics 112, 310-327.

Persson, T. Roland, G. and Tabellini,G. (2000) “Comparative Politics and Public Finance”, Journal of Political Economy vol. 108 (6), pp. 1121-1161

Persson, T. Roland, G. and Tabellini,G. (2003) “How do Electoral Rules Shape Party Structure, Forms of Government and Economic Policy?” Mimeo.

Przeworski, A. M. Alvarez, J. Cheibub, F. Limongi (2000) Democracy and Development, Political Institutions and Well-Being in the World, 1950-1990 Cambridge University Press, Cambridge.

Qian, Y. (2002), “How Reform Worked in China?”, Mimeo, UC Berkeley/

Qian, Y. G. Roland and C. Xu (1999) "Coordinating Changes in M-form and U-form Organizations" mimeo Stanford University.

Qian, Y. and C. Xu (1993) “Why China's Economic Reforms Differ: The M-Form Hierarchy and Entry/Expansion of the Non-State Sector" Economics of Transition, 1(2), pp. 135-170.

Rodrik, D. (2000) “Institutions for High-Quality Growth: What They Are and How to Acquire Them” Studies in Comparative International Development.

Roland, G. (1989) Economie politique du système soviétique, Editions de l’Harmattan, Paris, 1989.

Roland, G. (1991) "The Political Economy of Transition in the Soviet Union”, European Economy, 49, 1993, pp. 197-216.

Roland, G. (2000) Transition and Economics: Politics, Markets and Firms. MIT Press 2000. 
Roland , G. (2002) “Ten Years After...Transition and Economics”, IMF Staff Papers vol. 48, Special Issue, 2002, pp. 29-52.

Sachs, J. and W. Woo, (1994) "Structural Factors in the Economic Reforms of China, Eastern Europe, and the Former Soviet Union,” Economic Policy.

Shleifer, A. and R. Vishny. 1994. "Politicians and Firms,” The Quarterly Journal of Economics. 109:4, pp. 995-1025.

Weingast, B. (1995), "The Economic Role of Political Institutions: Market-Preserving Federalism and Economic Growth", Journal of Economics, Law and Organization, 11, 1-31.

Weitzman, M. and C. Xu (1993) “Chinese Township and Village Enterprises as Vaguely Defined Cooperatives”, Journal of Comparative Economics(3)1: 276-308.

Williamson, O. (1975), Markets and Hierarchies, Free Press, New York.

Williamson, O. (1985), The Economic Institutions of Capitalism Free Press, New York.

\footnotetext{
${ }^{1}$ Of course, this is an empirical question as well, given that no formal model can capture all the potentially relevant factors.

${ }^{2}$ This has led some, like Jeffrey Sachs and others, to argue that the "big bang" approach to transition, whereby all institutions are changed simultaneously and as fast as possible, is the only one possible. The existence of complementarities, however, does not rule out certain forms of gradualism. Indeed, as I have emphasized in my work on transition (see e.g., Roland 2000), a gradualist strategy may even be superior, as the Chinese experience has demonstrated. Institutional complementarities point to the art of reform sequencing as one of the most difficult in the transition process. Transition is akin to changing the engines of a plane while the plane is still flying.

${ }^{3}$ This does not mean that the speed of change of slow-moving institutions is constant over time. There can be periods of relatively faster change. For example, after Christianity became the official religion of the Roman Empire and after the establishment of the caliphate following the death of Mohammed, one can imagine that the spread of Catholicism and Islam was faster. It would, however, be wrong to think that millions of people thereafter drastically changed their world view and values as a result of forms of forced conversion. This would be a severe overestimation of state capacity in those days. It is only in the twentieth century (and maybe in the late nineteenth century) that governments have acquired the capacity of totalitarianism.

${ }^{4}$ A major exception is Weitzman and Xu (1993), who argue that the very strong development of township and village enterprises in China, despite the absence of well-defined property rights, can be traced back to cultural differences between Western and Chinese values.

${ }^{5}$ See Peter Evans (this issue).

${ }^{6}$ This should not, however, lead us to conclude that there is necessarily a deterministic relationship between initial material conditions and future economic development; many other factors play a key role.

${ }^{7}$ What follows is very schematic. Reality was more complex, but I want to get to the gist of the story.

8 The relevance of the Chinese experience is often dismissed because of the dictatorial character of its regime. However, it is interesting to note that, despite the political regime, it is not the case that painful reforms have been brutally imposed on the population. On the contrary, both the sequencing and the design of reforms have been tailored so as to benefit a majority without hurting a minority. The choice of dual-track price liberalization was
} 
therefore precisely designed to be Pareto-improving. It is not clear that the Chinese reform process would have been politically infeasible if China had not been a democracy or whether no democratic system could have sustained such a process. If anything, the absence of democracy has made it more difficult to enforce private property rights and the rule of law and to encourage the development of a sui generis private sector. Recent research (Che and Qian 1998) suggest that the development of township and village enterprises was a spontaneous response to the specific Chinese institutional situation with absence of the rule of law and the absence of sufficient safeguards against predatory government behavior. 